\title{
Effects of Different Extraction Methods and Process Conditions in the Yields of Avocado Oil
}

\author{
S.T. Mgoma ${ }^{1}$, L. Gutu ${ }^{1}$, M. Basitere ${ }^{1}$ and V Mshayisa ${ }^{2}$
}

\begin{abstract}
South Africa is one of the highest producers of avocado fruit in the world, with an annual growth of the industry and a potential leading producer. This growth gives potential for avocado oil production industry of high economic importance. This study therefore explores different extraction methods with different process conditions to find the optimum method and conditions for a high oil yield from avocados. This was done by extracting oil from Hass avocados from South African cultivars using different methods and applying different process conditions. The extraction methods that were explored are solid-liquid extraction with hexane solvent and microwave-aided solvent extraction. The process conditions that were explored are different solid to liquid ratio; different extraction/residence times and continuous extraction with fresh solvent. The efficiency of all these methods and conditions were measured based on their oil yields. The objective of the study was to find optimum conditions to produce more avocado oil using fewer resources.
\end{abstract}

Keywords- Avocado oil, Extraction, Optimum, Process conditions, Yield

\section{INTRODUCTION}

Avocado is a fruit with extremely high oil content, which is the main component of its dry weight. The fruit is highly nutritious, rich in antioxidants and vitamins. These are vitamins A, B, C and E, carotenoids, tocopherols and sterols that possess antioxidants. It is also found that these nutritional components are also found in its oil. The use of avocado oil for culinary purpose and for cosmoceutics use as an essential oil makes it of high economic importance. Because of the economic importance and potential of this oil; it becomes appropriate to further investigate the detailed changes that the oil undergoes when different extraction methods and conditions are used to extract the oil [5]. This study is aimed at providing data of optimum process condition that can help design and optimize oil producing processes to operate efficiently. Optimization is known as an act of obtaining the best possible results or the effort of achieving the optimal solution under the given set of circumstances [2]. The current avocado oil industry relies on the rejects fruit from the export and retail industry [9]; this is due to the costs of oil production with a high grade avocado. It is

Manuscript received 10 October 2019. This work was supported in part by the Cape Peninsula University of Technology (CPUT). Special thanks to Bioresource Engineering Research Group (BioERG) for the support towards this project; you made this work possible.

${ }^{1}$ Cape Peninsula University of Technology, Department of Chemical Engineering, P.O. Box 1906, Bellville 7535, South Africa

${ }^{2}$ Cape Peninsula University of Technology, Department of Food Science and Technology, P.O. Box 1906, Bellville 7535, South Africa therefore important to find the optimal solution for avocado oil extraction process that will yield the more oil with less effort and resources. Qin \& Zhong [6], however argues that a suitable extraction method depends not only on the yield of the oil but also on the chemical composition and quality of the oil produced.

\section{MATERIALS AND METHODS}

\section{Fruit Preparation and Pretreatment}

The avocado fruit were attained from a fruit and vegetable market wholesale. The avocado fruit type chosen to be studied was the Haas variety; the fruits were all sourced from local South African farms. The Haas avocado is the most grown variety in South Africa; according to the South African Avocado Growers Association (SAAGA), approximately 70\% of avocado trees in South Africa are Haas variety. This proves to be a variety that has a high potential to supply the oil production industry in South Africa. The fruits were purchased unripe from the wholesale; they were then left in the laboratory for 5 days at ambient temperature to ripen. Avocado is a tropical fruit that matures on the tree and ripens once fallen or harvested from the tree [7]. The ripening of the fruit before extraction was based on a study by Mostert et al., [4] who studied the yield of oil between ripe and unripe avocados. When the fruits were ripe they were then peeled and deseeded; because the oil was to be extracted from the mesocarp of the avocado while the seed and peels are considered as waste. The mesocarp was then meshed up with the blender and a fork to form a paste. The paste then needed to be pretreated to remove most of the moisture before extraction may take place. This is to increase the rate of reaction (extraction). According to Qin \& Zhong [6], the moisture content of the avocado pulp interferes with the effect of extraction; hence pretreatment is important before extraction takes place. The paste was oven dried using Labotec air draft oven for 24 hours at $70^{\circ} \mathrm{C}$. The dried avocado mesocarp paste was then stored in a cool dark place at a temperature below $20^{\circ} \mathrm{C}$.

\section{Choice of Solvent}

Therefore, since this study will be looking at solvent extraction methods; it was important to first look into the suitable solvent to use for oil extraction. According to FAO/WHO Expert Committee [1] only 17 organic solvents were allowed to be used for food and personal care products. These solvents are known as GRAS (Generally Regarded as Safe) solvents. According to Kumar [2] the choice of solvent 
should be selected based on the availability, price, properties like boiling point to allow easy recovery with evaporation, toxicity, solvent power and it should be non-hygroscopic. The solvent chosen for this study was hexane; this is due to its dielectric value which makes it a non-polar solvent and favourable to extract non-polar compounds like oil. The other factor considered in choosing hexane was its low boiling point and low latent heat of vaporization and lastly, it is highly selective. Therefore, this solvent will dissolve the oil mostly due to its selectivity and dielectric constant value.

The hexane used in this study for extraction was lab grade solvent.

\section{Hexane Extractions}

The hexane extractions were all performed at room temperature with no heat applied to during extraction. The extractions took place in glass Erlenmeyer flasks with just the dried avocado paste and the hexane solvent. All the extractions were done with $50 \mathrm{~g}$ avocado sample; the extractions were done at different operating conditions. The extractions were all done in pairs as duplicates, sample A and sample B; to assure the credibility of the experiment and results.

The different conditions that were applied to the extractions were solid-liquid ratios of the avocado and the solvent. The ratios explored were $1: 1,1: 2$ and 1:3. The other process condition explored was the extraction time, times chosen were 2 hours, 4 hours and 6 hours.

The extraction was also done using different methods with hexane; these were macerations and microwave-aided extraction. Maceration was done in three (3) stages with one (1) hour extractions. The avocado was placed in a flask and extraction took place for an hour, then the solution was filtered and the solid avocado was placed in another fresh solvent for another hour. This was done in three stages.

The microwave-aided extraction was done by a pretreatment of the avocado in a microwave oven before extraction. The avocado paste was placed over the turning plate inside the oven; the microwave was set on maximum power output of $1000 \mathrm{~W}$ for ten (10) minutes. The microwave used was a Samsung model: MS103HCE. After being put out the microwave it was allowed to cool down. Thereafter was then extracted with hexane in an Erlenmeyer flask.

In all the experiments performed, the samples were filtered with vacuum to recover the solid after extraction. The liquid solution of the solvent and oil was then separated using a rotary evaporator, where the hexane and the oil were recovered separately.

\section{RESULTS AND DISCUSSION}

\section{Effect of extraction time}

The yield of oil extracted from the avocado paste showed to have had an increase with the increase in time. According to Table 1, the results show a significant difference in the amount of oil extracted with difference in time that the avocado is allowed to stay in the solvent. The relationship is also found to be very close to linear according to the yield against time chart shown in figure 1.

TABLE I: OIL YIELD (G/KG AVOCADO MESOCARP ON A DRY WEIGHT BASIS) FROM THE AVOCADO FRUIT AFTER EXTRACTION WITH HEXANE AT DIFFERENT EXTRACTION TIMES.

\begin{tabular}{|c|c|}
\hline Time (hrs) & Yield (g/Kg) \\
\hline \hline 2 & $337 \pm 8$ \\
4 & $432 \pm 23$ \\
6 & $541 \pm 31$ \\
\hline
\end{tabular}

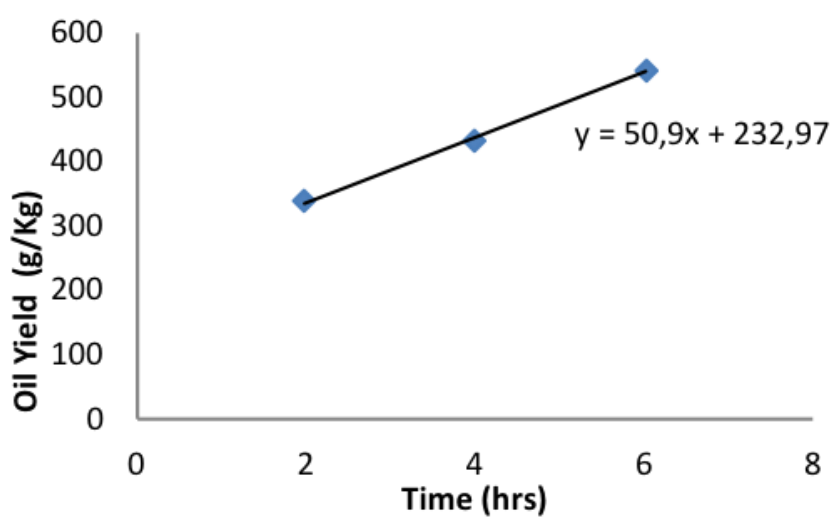

Fig 1: Oil Yield Vs Extraction time

Although the results show an increase of oil extracted, the data point are found to be few to explain the point of exhaustion, which is the time which releases the maximum amount of oil from the avocado. According to Lloyd \& van Wyk [3] during diffusion; there is high concentration of the solute in the feed and it decreases with time as it diffuses through the solvent over time. It is therefore recommended that further experiments explore the extraction time further than 6 hours.

The gradient of the best fit line was found to be 50.9; this then tell us that from these results the rate of oil extraction was approximately 50.9 grams per hour $(\mathrm{g} / \mathrm{hr})$.

\section{Effect of solid-liquid ratio}

The effect of the solid to liquid ratio of the avocado solid to the hexane solvent liquid was explored. The extraction was done keeping the extraction time constant while changing the ratio. All the extractions were done at a constant time of four (4) hours.

TABLE II: OIL YIELD (G/KG OF AVOCADO MESOCARP ON A DRY WEIGHT BASIS) FROM AVOCADO FRUIT AFTER EXTRACTION WITH HEXANE AT DIFFERENT SOLID TO LIQUID RATIOS.

\begin{tabular}{cc}
\hline Ratio & Yield $(\mathbf{g} / \mathbf{K g})$ \\
\hline \hline $1: 1$ & $245 \pm 27$ \\
$1: 2$ & $432 \pm 23$ \\
$1: 3$ & $272 \pm 16$ \\
\hline
\end{tabular}




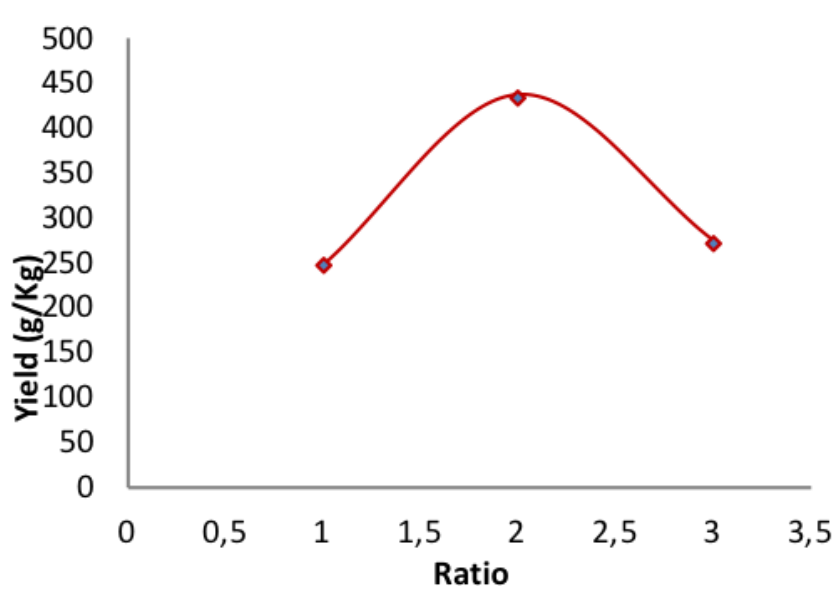

Fig 2: Oil Yield Vs Solid to Liquid Ratio

The results show that the solid to liquid ratio of the avocado and the solvents have an optimum of ratio 1:2. This ratio gave the highest oil yield compared to the ratios of $1: 1$ and 1:3. This proves that there is an optimum solid to liquid ratio in extraction, therefore, more solvent does not necessarily result in a higher rate of extraction, neither does less solvent. According to Lloyd \& van Wyk [3] diffusion takes place predominantly on the interfaces between the feed material and the solvent known as diffusion layers. They argue that the diffusion layers also act as resistance to diffusion; therefore, even if the solvent is in excess, the rate of diffusion is determined by what takes place at the diffusion layers interfaces.

\section{Oil extraction by macerations}

Avocado oil was also extracted by the use of macerations; where a series of extractions are done. After an hour of extraction, the mixture was filtered and fresh solvent was added to the avocado. This was done with a solid to liquid ratio of $1: 2$, it was kept constant and the extraction time was also kept constant at every 1 hour.

TABLE III: OIL MASS (GRAMS) OF OIL EXTRACTED AFTER EVERY HOUR OF THE MACERATIONS. THE TOTAL MASS IS SHOWN BELOW WITH THE YIELD (G/KG OF AVOCADO MESOCARP ON WEIGHT BASIS).

\begin{tabular}{c|c}
\hline Time $(\mathbf{h r})$ & Mass of oil (g) \\
\hline \hline 1 & $11.10 \pm 0.16$ \\
2 & $3.43 \pm 0.25$ \\
3 & $2.48 \pm 0.60$ \\
\hline Total & $17.01 \pm 0.15$ \\
\hline Yield & $340 \mathrm{~g} / \mathrm{Kg} \pm 3$ \\
\hline
\end{tabular}

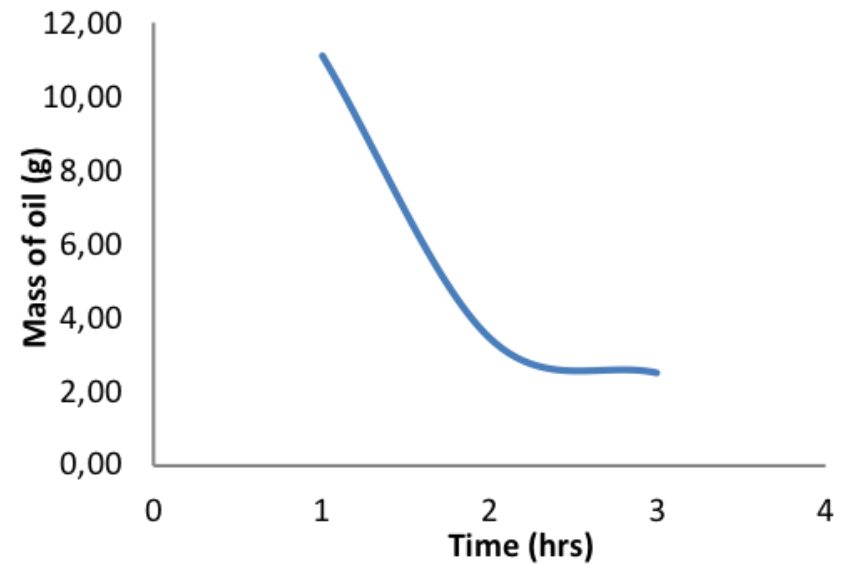

Fig 3: Mass of Oil Extracted Over Time

The effect of a different extraction mode with hexane shows a slight difference. According to Fig 3; using fresh solvent every hour helps observe the rate of extraction over time at every hour. This curve confirms Fick's law in diffusion that the rate of diffusion is driven by the concentration difference of the solute between feed and the solvent [8]. Fig 3 shows that more oil was extracted in the first hour of extraction or the first maceration; the rate and mass of extraction then decreases as the concentration of the solute decreases from the feed and increases in the bulk solution of the solvent [3].

\section{Oil yield vs amount of solvent used}

The relationship and effect of the amount of solvent used to the oil yield after extraction was studied to help optimize the extraction process. The data was gathered from the different experiments done with the time kept constant while varying the amount of solvent used in that experiment.

TABLE IV: RELATIONSHIP BETWEEN THE OIL YIELD AND THE AMOUNT OF SOLVENT USED FOR EXTRACTION

\begin{tabular}{|cc|cc|}
\hline $\begin{array}{c}\text { Solvent used } \\
(\mathbf{m L})\end{array}$ & Yield (g/Kg) & Method & Time \\
\hline 76.34 & $245 \pm 27$ & $1: 1$ Ratio & 4 hours \\
152.67 & $432 \pm 20$ & $1: 2$ Ratio & 4 hours \\
229.01 & $272 \pm 12$ & $1: 3$ Ratio & 4 hours \\
458.01 & $340 \pm 3$ & $\begin{array}{c}1: 2 \text { ratio } \\
\text { macerations }\end{array}$ & $\begin{array}{c}\text { 3 x 1-hour } \\
\text { macerations }\end{array}$ \\
\hline
\end{tabular}




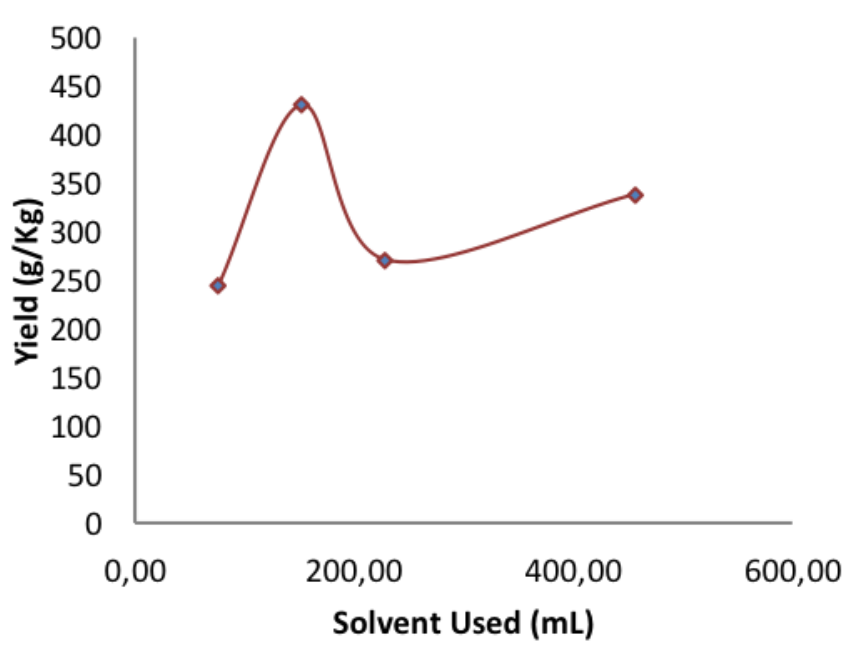

Fig 4: Amount of Solvent Used Vs Oil Yield

The data showed no trend or real relationship between the amount of solvent used and the oil yield. Therefore, the more solvent used to in the extraction of avocado oil does not guarantee a higher yield of oil. Therefore, from an economic stance, it is wasteful to choose and operate an extraction process that uses any ratio above 1:2. Therefore with the focus on the study to optimize the extraction process with hexane; it is very important to notice the optimum amount of solvent needed for a higher rate of extraction.

\section{Microwave-aided extraction}

The microwave aided solvent extraction was done to evaluate the effect of microwave pretreatment compared to that of oven drying.

TABLE V: OIL YIELD (G/KG AVOCADO MESOCARP ON DRY WEIGHT BASIS) AFTER HEXANE EXTRACTION WITH AID OF MICROWAVE PRETREATMENT.

\begin{tabular}{|c|c|c|c|}
\hline Pretreatment & $\begin{array}{c}\text { Oil Yield } \\
\text { (g/Kg) }\end{array}$ & $\begin{array}{c}\text { Solid-liquid } \\
\text { ratio }\end{array}$ & $\begin{array}{c}\text { Extraction } \\
\text { Time }\end{array}$ \\
\hline \hline $\begin{array}{c}\text { Microwave } \\
(10 \text { min) }\end{array}$ & $329 \pm 4$ & $1: 2$ & 2 hours \\
\hline $\begin{array}{c}\text { Oven Dried } \\
(24 \text { hours })\end{array}$ & $337 \pm 8$ & $1: 2$ & 2 hours \\
\hline
\end{tabular}

The optimum conditions for the microwave pretreatment was taken from a study by Ortiz Moreno et al., [5] who studied the effect of sample exposure time in the microwave to the yield of the avocado oil. Therefore the optimum exposure time and power conditions used in this study were taken from Ortiz Moreno et al., [5] paper. In this part of the study, it was aimed to compare the difference in oil yield between oven dried samples and the microwave pretreated samples after extraction with hexane for 2 hours. The results then show that on average, the oven dried samples yielded more oil than microwave pretreated samples. However; with the deviation allowances range, the yields are actually the same on average. The oven dried samples are only slightly higher.
These results prove that the two pretreatment methods give the same yield of oil when extracted with hexane. However; although the oil yield may be similar, according to Ortiz Moreno et al., [5] oil extracted with aid of microwave pretreatment gave a lower quality oil than that which was oven dried. The microwave-aided extracted oil had higher levels of volatiles than the oil extracted from oven-dried samples. Ortiz Moreno et al.,[5] also found oil extracted from microwave pretreated samples to have lower unsaturated fatty acid content compared to that of oven dried samples.

\section{CONCLUSION}

The results of these experiments will provide data to help design an efficient solvent extraction process for avocado oil. This process should also be suitable and practical for implementation for commercial production. Therefore, the optimum extraction method and condition is that which will be producing a high yield of oil with fewer resources and must be suitable to use in industry. The suitable extraction method depends not only on the yield of the oil but also on the chemical composition and quality of the oil produced. It is therefore also sensible that in order to receive more value in the oil produced from avocado; the oil must be of high quality in order to be used in food, pharmaceutical and cosmetic industry. We can therefore say that from the high oil content of the Haas avocados in South Africa and the high yields found from extraction methods and conditions with hexane; the avocado oil industry in South Africa has great potential. These results also prove that avocados may also be considered a primary source of oil for the food and pharmaceutical industries because of its nutritional value and availability in the South Africa. The avocado availability in South Africa does not only depend on the commercial farmers; but it has potential for local farmers in the north eastern part of the country which is known to be a sub-tropical climate.

\section{RECOMMENDATIONS}

The experiments conducted evaluated the process conditions and extraction methods only and not necessarily the costs directly. However, from a general view, the processes that require the use of energy can be estimated and assumed to have a higher cost. Furthermore; the amount of solvent used in the extraction process can be assumed to be proportional to the cost of production. Therefore, from the results of the experiments, it was found that there is an optimum solid to liquid ratio which will help to control the amount of solvent used for extraction. It was also found that a significant yield of oil can be extracted without the aid of heat during extraction process. This reduces the use of energy which can be stored to use for pretreatment and solvent recovery.

\section{REFERENCES}

[1] FAO/WHO Expert Committee. in COMPEDIUM OF FOOD ADDITIVE AND SPECIFICATION. Summary and Conclusions. 2018

[2] D.S. Kumar, Herbal Bioactives and Food Fortification. Boca Raton, Florida., CRC Press, 2015, ch 2-3 pp. 29-128 
https://doi.org/10.1201/b19275

[3] P. Lloyd, \& J. van Wyk, Introduction to Extraction in Food Processing. in Enhancing Extraction processes in the Food Industry. Boca Raton, Florida.,CRC Press, 2012, ch $1: 1-24$. https://doi.org/10.1201/b11241-2

[4] M.E. Mostert, B.M. Botha, L.M. Du Plessis, \& K.G. Duodu., Short Communication Effect of fruit ripeness and method of fruit drying on the extractability of avocado oil with hexane and supercritical carbon dioxide. , 2885(June): 2880-2885., June 2007 https://doi.org/10.1002/jsfa.3051

[5] A. Ortiz Moreno, L. Dorantes, J. Galíndez, \& R.I. Guzmán. Effect of different extraction methods on fatty acids, volatile compounds, and physical and chemical properties of avocado (Persea americana Mill.) oil. Journal of Agricultural and Food Chemistry, 51(8): 2216-2221. , February 2003 https://doi.org/10.1021/jf0207934

[6] X. Qin, \& J. Zhong., A Review of Extraction Techniques for Avocado Oil. Journal of Oleo Science, 65(11): 881-888., January 2016 https://www.jstage.jst.go.jp/article/jos/65/11/65_ess16063/_article.

[7] M. Reddy, R. Moodley, \& S.B. Jonnalagadda., Fatty acid profile and elemental content of avocado (Persea americana Mill.) oil -effect of extraction methods. Journal of Environmental Science and Health - Part B Pesticides, Food Contaminants, and Agricultural Wastes, 47(6): 529-537., March 2012 https://doi.org/10.1080/03601234.2012.665669

[8] J. Richardson, J. Harker, \& J. Backhurst, Coulson and Richardson's Chemical engineering. Fifth ed. Oxford: Butterworth Heinemann. 2002. ch 10 , pp. $502-540$ https://doi.org/10.1016/B978-0-08-049064-9.50021-7

[9] A. Woolf, M. Wong, L. Eyres, T. McGhie, C. Lund, S. Olsson, Y. Wang, C. Bulley, M. Wang, E. Friel, \& C. Requejo-Jackman, Avocado Oil. in Gourmet and Health-Promoting Specialty Oils., Urbana, IL, AOCS Press, 2009. ch 2: $73-125$ https://doi.org/10.1016/B978-1-893997-97-4.50008-5

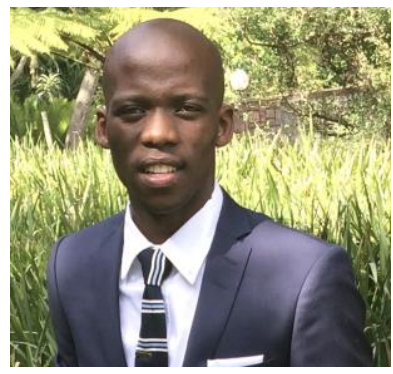

Shaun Thamsanqa Mgoma - This author was born on 09 September 1990 in Kimberley, Northern Cape, South Africa; became a Member of the BioERG group under the Chemical Engineering department of Cape Peninsula University of Technology in 2019. The author completed a Btech degree in Chemical Engineering from the Cape Peninsula University of Technology (CPUT), in Cape Town, South Africa in the year 2012. He further obtained a Postgraduate diploma in Business Administration from the University of the Western Cape (UWC) in Cape Town in the year 2019. Shaun was part of the graduate training program at Rheinmetall Denel Munitions in the year 2013. In 2014 he was then appointed a Team leader of nitration (esterification) at the Nitrocellulose plant. Through his outstanding work, he was then appointed a Plant Supervisor of the whole Nitrocellulose manufacturing plant in 2015. In the year 2018; Shaun was also a part of the Entrepreneurship and Empowerment in South Africa (EESA) program under the University of Western Cape (UWC) with University of Florida (UF) and University of Colorado (UC) from the United States of America (USA). In this program Shaun was a consultant in a Business consultation team. He headed the operations and management division of the consulting team. The program worked with Small, micro and medium enterprises (SMME) in the Western Cape, offering them business consultation and solutions to rebuild, grow and sustain their businesses. 